Special Issue of the 6th International Congress \& Exhibition (APMAS2016), Maslak, Istanbul, Turkey, June 1-3, 2016

\title{
Mechanical Properties and Fracture Analysis of Clinched Joints in Titanium Sheet Materials
}

\author{
X.C. HE* , L. LeI, Y. Zhang And B.Y. XinG \\ Innovative Manufacturing Research Centre, Faculty of Mechanical and Electrical Engineering, \\ Kunming University of Science and Technology, Kunming, 650500, P.R. China
}

\begin{abstract}
Mechanical fastening techniques are used extensively in different industry fields for joining various materials in the assembly of components and structures. The use of mechanical clinching is of interest to different industries such as aerospace, automotive, packaging and domestic appliance. This, together with increasing use of light-weight materials, has produced a significant increase in the use of mechanical clinching in light-weight structures in recent years. This paper deals with the mechanical properties and fracture analysis of extensible die clinched joints in the dissimilar metal sheets combinations of titanium sheet material and aluminum sheet material. Tensile-shear tests were carried out to characterize the mechanical properties of different clinched joints made of the dissimilar metal sheets combinations. The normal hypothesis tests were performed to examine the rationality of the test data. The load-bearing capacity and failure modes of different titanium sheets clinched joints were studied. Results showed that most titanium sheets clinched joints failed in the neck fracture mode. Results also showed that the load-bearing capacity of clinch joints with titanium as upper sheets is higher than that of the clinched joints with titanium as lower sheets.
\end{abstract}

DOI: 10.12693/APhysPolA.131.16

PACS/topics: 46.70.-p

\section{Introduction}

Advanced joining technology is an integral part of the manufacturing processes of lightweight structures. Many efforts have been spent to develop the suitability of various joining processes for application into lightweight structures [1-3]. The use of clinching is of great interest to many industrial sectors including aerospace and automotive. This, together with increasing use of light weight materials which normally are difficult or impossible to weld, has produced a significant increase in the use of clinching technology in engineering structures and components in recent years [4-6].

In industrial applications of the clinched structures, knowledge of the mechanical characteristics of clinched joints is very important. The static and dynamic behavior of clinched joints has been the subject of a great amount of numerical and experimental studies. An investigation on clinching mechanism has been conducted by Gao and Budde [7]. Some elementary terms were used to establish a basic theory for analyzing the clinching mechanism. The influence of the clinching process parameters on the join-ability of high-strength steel was studied by Mucha [8] using finite element (FE) method. The results showed that some parameters, such as die radius, die depth, and die groove shape were mainly affected on the join-ability. The suitability and economics of clinching processes were studied by Varis $[9,10]$.

Another clinching configuration has been developed involving an extensible die for improving the mechani-

*corresponding author; e-mail: xiaocong_he@163.com cal behavior of clinched joints. The use of extensible die clinching has increased in recent years. The influence of process parameters in extensible die clinching has been systematically investigated by Lambiase and colleagues $[11,12]$. The extensible die clinched joints were produced under different forming loads for evaluating the evolution of the joints' profile experimentally.

Titanium sheets have excellent strength, ductility, corrosion resistance, and have been widely used in aerospace engineering. Dissimilar sheet joints of titanium sheets with other lightweight alloys have also been widely used in aerospace and metallurgical industries. The fusion welding and friction stir welding techniques were normally used to join similar and dissimilar metal sheets of titanium sheets. As those techniques are metallurgical joining process, the micro-structure of welding region can be affected, which influences the mechanical property of joint consequently. In addition, those techniques need welding materials and extra equipment to discharge the exhaust gas, which increases manufacture costs and the pressure of environment. It is widely accepted that similar and dissimilar metal sheets of titanium with other lightweight alloys can be jointed well by clinching. However, no investigation on such clinched joints has been reported so far.

Present paper reports experiments on the mechanical properties of single lap extensible die clinched joints between dissimilar metal sheets of TA1 titanium material with 5052 aluminum alloy. Tensile-shear tests were carried out to characterize the mechanical properties of different clinched joints made of the dissimilar metal sheets combinations. Force-displacement curves were obtained in order to characterize the tensile-shear properties of the joints. The load-bearing capacity and failure modes of different titanium sheets clinched joints were studied. 


\section{Specimens preparation}

\subsection{Material tests}

The sheet materials tested in present study were TA1 titanium and AA5052 aluminum alloy plates with $1.5 \mathrm{~mm}$ thickness. All plates were cut along rolling direction. The material properties were measured by an extensometer of MTS 634.31F-24 with $20 \mathrm{~mm}$ gauge length on an MTS servo hydraulic test machine. The engineering stressstrain curves at a constant cross head speed of $5 \mathrm{~mm} / \mathrm{min}$ are shown in Fig. 1. It can be seen that TA1 titanium plates and AA5052 aluminum alloy plates have excellent ductility, which is a prerequisite for clinching.

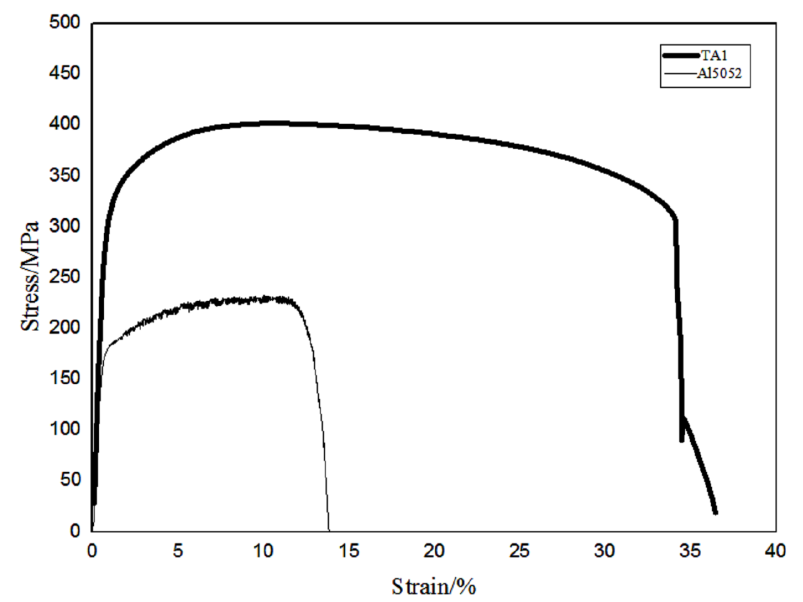

Fig. 1. Stress-strain curves for sheet materials.

\subsection{Specimen configuration}

As shown in Fig. 2, a single lap extensible die clinched joint comprises an upper sheet, lower sheet. The sheet materials tested were TA1 titanium plates and AA5052 aluminum alloy plates of dimensions $110 \mathrm{~mm}$ length $\times$ $20 \mathrm{~mm}$ width $\times 1.5 \mathrm{~mm}$ thickness and were joined together in the central part of lap section. In order to make

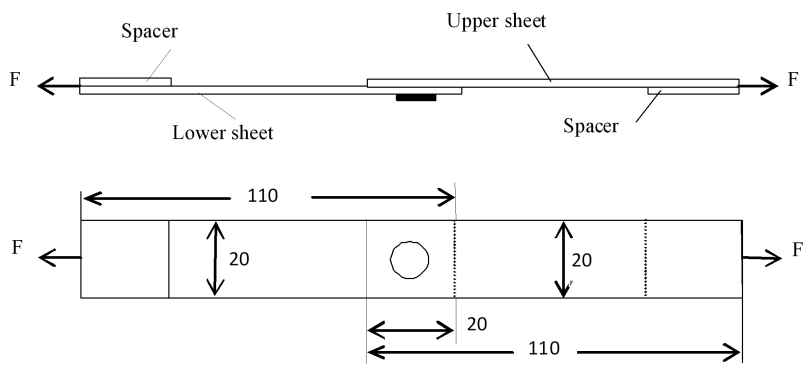

Fig. 2. Configuration and boundary condition of a single lap clinched joint (dimensions in $\mathrm{mm}$ ).

it easy to describe the single lap extensible die clinched joints with different sheets, the following nomenclature is used:

- T-A joint: clinched joints with dissimilar metal sheets of TA1 titanium (upper sheet) and AA5052 aluminum alloy (lower sheet),
- A-T joint: clinched joints with dissimilar metal sheets of AA5052 aluminum alloy (upper sheet) and TA1 titanium (lower sheet).

\subsection{Specimens preparation}

A clinching equipment RIVCLINCH 1106 P50 system was employed as clinching machine. In the extensible die clinching process material is spread radially and results in an interlock. The extensible die clinched joints are characterized by different geometrical and mechanical properties. The flat bottom extensible die is made of high strength steel. For easy clinching, TA1 titanium sheets were heated to $700^{\circ} \mathrm{C}$ by oxyacetylene flame gun. All clinched joints were formed for the same depth sensor. Figure 3 shows different clinched joints studied in present paper.

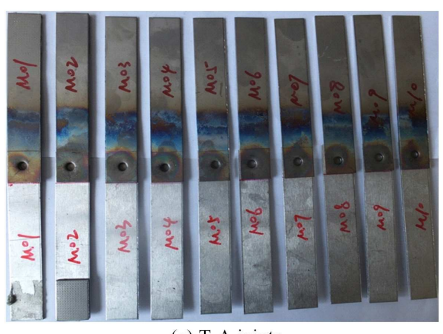

(a) T-A joints

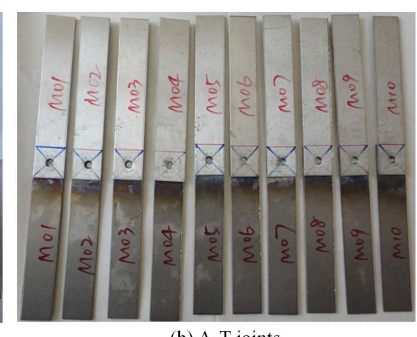

(b) A-T joints
Fig. 3. (a) T-A and (b) A-T clinched joints.

\section{Typical failure modes of clinched joints}

The mechanical properties of the clinched joints are dependent on the process of clinching in which both upper and lower sheets undergo plastic deformation and resilience to form a mechanical interlock. During the clinching process, the upper sheet undergoes a significant thinning near the punch corner radius. The strength of an extensible die clinched joint depends on the joint profile and particularly on the neck thickness, the magnitude of the produced undercut and final bottom thickness, as shown in Fig. 4.

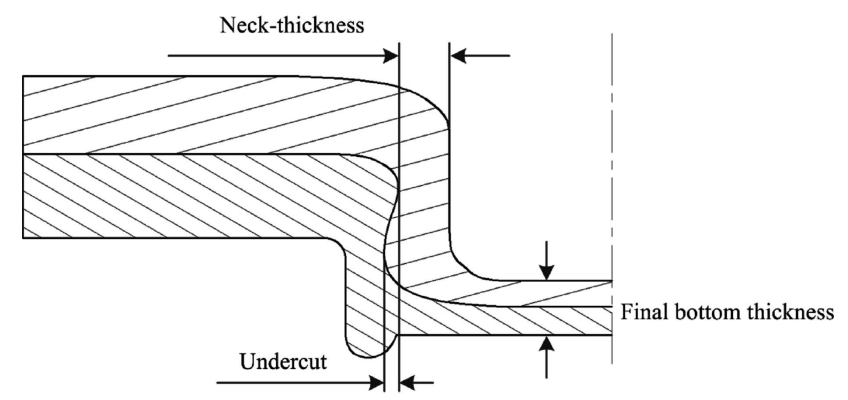

Fig. 4. Quality assessment criteria of clinched joint.

The typical failure modes of clinched joints are, depend on the joint profile and loading conditions, the neck fracture mode and button separation mode as shown in Fig. 5. The neck fracture mode normally results 
from small neck thickness and button separation mode normally results from small undercut. Small bottom thickness will lead to strength decrease or even bottom crack of clinched joints.
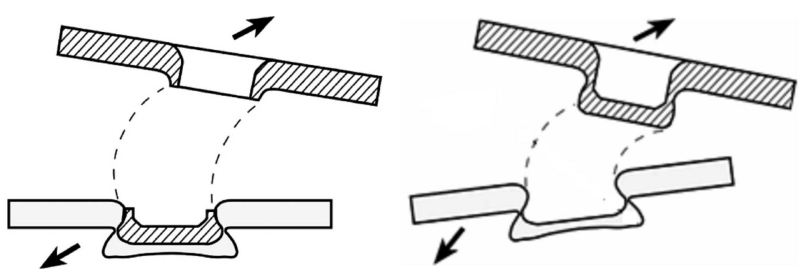

Fig. 5. Typical failure modes of clinched joints.

(a) Neck fracture mode, (b) button separation mode.

\section{Tensile-shear tests and results analysis}

\subsection{Tensile-shear tests}

Tensile-shear tests were carried out to characterize the mechanical properties of $\mathrm{T}-\mathrm{A}$ and $\mathrm{A}-\mathrm{T}$ clinched joints. A servo-hydraulic testing machine was used in the tensileshear tests of $\mathrm{T}-\mathrm{A}$ and $\mathrm{A}-\mathrm{T}$ joints. The distance between two grips was about $100 \mathrm{~mm}$. The upper end of each of the joints was fixed, and a quasi-static downward displacement load was applied to the lower end. As shown in Fig. 1, spacers with the sheet thickness were used on both ends of the specimens to centralize the load and reduce the influence of additional bending on the joints during the tests. The tests were performed with a constant displacement rate of $1 \mathrm{~mm} / \mathrm{min}$ and terminated when the sheets were separated or the force drops to $20 \%$ of the peak force value. For each test, ten samples were mechanically tested. Continuous records of the applied forcedisplacement curves were obtained during each test.

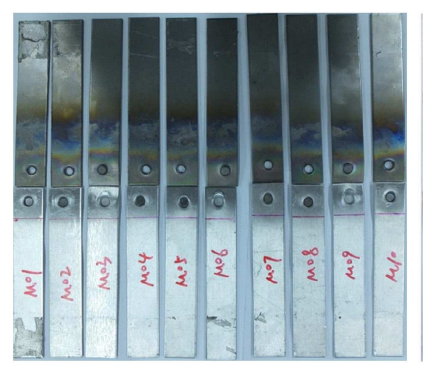

(a) Failed T-A joints

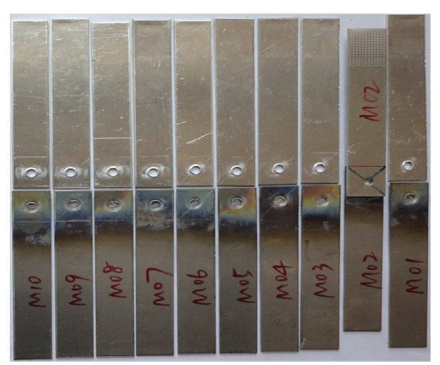

(b) Failed A-T joints
Fig. 6. Failed (a) T-A and (b) A-T joints.

Figure 6 shows failed $\mathrm{T}-\mathrm{A}$ and $\mathrm{A}-\mathrm{T}$ clinched joints. It is obvious that for most clinched joints, the failure mode is the neck fracture mode. In $\mathrm{T}-\mathrm{A}$ joints seven joints were failed with neck fracture mode and three joints were failed with button separation mode. In $\mathrm{A}-\mathrm{T}$ joints, however, nine joints were failed with neck fracture mode and not completely separated for one sample. Under the tensile-shear load, the neck of upper sheet bear a main shear load by geometrical interlocking. When the shear stress reaches the yield criterion of sheet material, a crack is initiated from the interfacial surface of the upper sheet and grows into the upper sheet thickness. After rowing into the upper sheet, crack kinks toward the button centre and then propagates along the circumference of the button neck of the upper sheet. Finally the inner button is sheared off at the neck. The button separation mode in $\mathrm{T}-\mathrm{A}$ joints could be attributed to a relative small undercut.

The force-displacement curves of $\mathrm{T}-\mathrm{A}$ and $\mathrm{A}-\mathrm{T}$ clinched joints are shown in Fig. 7. To enable easy comparison, all force-displacement curves were drawn using the same coordinate scales. It is interesting to note from Fig. 7 that the load-bearing capacity of $\mathrm{T}-\mathrm{A}$ clinch joints which with TA1 titanium as upper sheets, is higher than that of $\mathrm{A}-\mathrm{T}$ clinched joints which with TA1 titanium as lower sheets. It can be seen from Fig. 7 that in the cases of the clinch joints failed with neck fracture mode, after the peak the force suddenly drops. In the case of the clinched joints failed with button separation mode, however, after the peak the force decreases gradually, as shown in Fig. 7a. It is also noteworthy that the strength reproducibility is higher for $\mathrm{A}-\mathrm{T}$ joints than for $\mathrm{T}-\mathrm{A}$ joints though the strength of $\mathrm{A}-\mathrm{T}$ joints is smaller than the strength of $\mathrm{T}-\mathrm{A}$ joints.

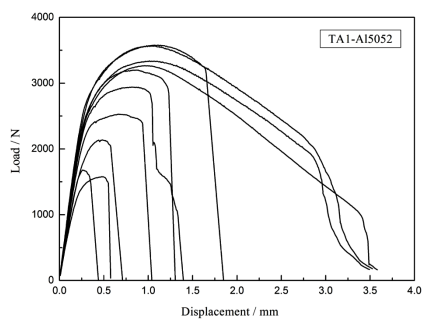

(a) T-A joints

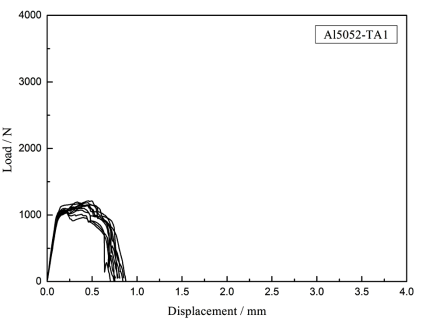

(b) A-T joints
Fig. 7. Force-displacement curves of (a) T-A and (b) A-T joints.

\subsection{Results analysis}

It is clear from Fig. 7 that the data for the failure load and failure displacement of $\mathrm{T}-\mathrm{A}$ and $\mathrm{A}-\mathrm{T}$ clinched joints were relatively stable, showing that the results were reliable and repeatable. To examine the rationality of the test data, the normal hypothesis tests were performed using MATLAB 7.0. The results show that the tensile-shear strength of $\mathrm{T}-\mathrm{A}$ and $\mathrm{A}-\mathrm{T}$ clinched joints follow normal distributions. All test data fitting the region bounded by the $95 \%$ confidence limits. The statistics of tensileshear tests for $\mathrm{T}-\mathrm{A}$ and $\mathrm{A}-\mathrm{T}$ clinched joints are shown in Table I.

\subsection{Fracture surface analysis}

The neck fracture mode shown in Fig. 6 was studied by means of a scanning electron microscope (SEM) to understand the microscopic fracture behavior of clinched joints in titanium sheet materials. Figure 8 shows the 
TABLE I

Statistics of tensile-shear tests for T-A and A-T joints.

\begin{tabular}{c|c|c|c|c|c|c}
\hline \hline Joints & $\begin{array}{c}\text { Average } \\
\text { load } \\
{[\mathrm{N}]}\end{array}$ & $\begin{array}{c}\text { Standard } \\
\text { deviation }\end{array}$ & $\begin{array}{c}\text { Variation } \\
\text { coefficients }\end{array}$ & $\begin{array}{c}\text { Confidence } \\
\text { interval } \\
{[\mathrm{N}]}\end{array}$ & $\begin{array}{c}\text { Average } \\
\text { failure } \\
\text { displacement } \\
{[\mathrm{mm}]}\end{array}$ & $\begin{array}{c}\text { Average } \\
\text { energy } \\
\text { absorption } \\
{[\mathrm{J}]}\end{array}$ \\
\hline $\mathrm{T}-\mathrm{A}$ & 2780.74 & 756.167 & 0.2716 & $(2342.43,3219.05)$ & 1.794 & 2.070 \\
$\mathrm{~A}-\mathrm{T}$ & 1131.176 & 58.112 & 0.0514 & $(1073.07,1164.86)$ & 0.786 & 0.624
\end{tabular}

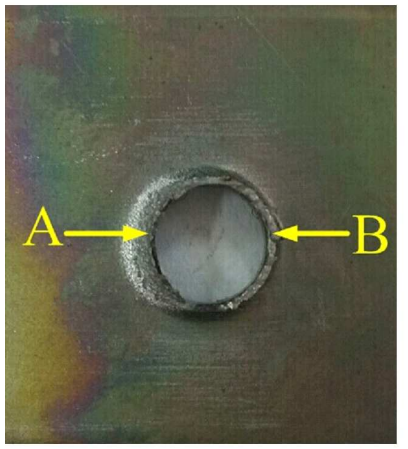

(a) Fracture appearance of the upper sheet

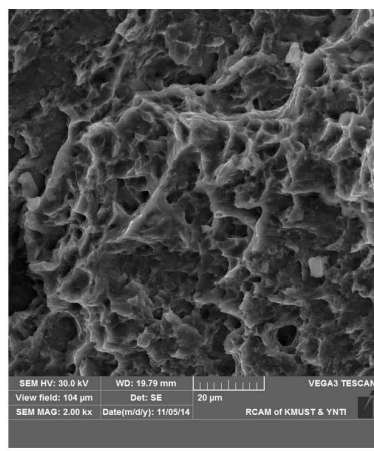

(b) SEM morphology of $\mathrm{A}$ area

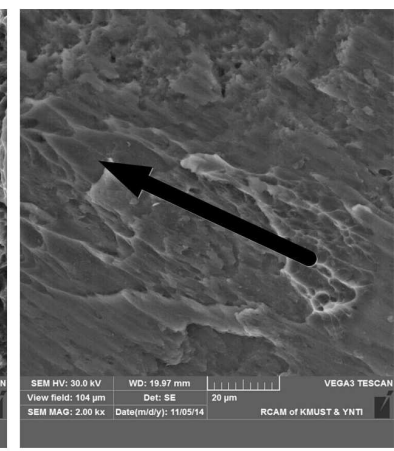

(c) SEM morphology of B area

Fig. 8. SEM analysis of the upper sheet (Ti) of a typical T-A joint. (a) Fracture appearance of the upper sheet, (b) SEM morphology of A area, (c) SEM morphology of B area.

SEM analysis of the upper sheet of a typical T-A joint. The shrinkage of the wall is evident at the load side (B area) with respect to the back area (A area). This suggests the presence of neck fracture mode based on plasticity phenomena and subsequent tear starting from the load side. The neck of upper sheet around clinched point had different degrees of tearing.

\section{Conclusion}

This paper mainly deals with the mechanical properties and fracture analysis of extensible die clinched joints in the dissimilar metal sheets combinations of titanium and aluminum sheet materials. Load-displacement curves were obtained to characterize the mechanical properties of the joints, and a statistical method was used to analyze the validity of the experimental data. The neck fracture mode was studied by means of SEM to understand the microscopic fracture behavior of clinched joints in titanium sheet materials. Results showed that most titanium sheets clinched joints failed in the neck fracture mode. Results also showed that the load-bearing capacity of clinch joints with titanium as upper sheets is higher than that of the clinched joints with titanium as lower sheets.

\section{Acknowledgments}

This study has been supported by the National Natural Science Foundation of China (grant No. 51565023) and Major Program Foundation of the Education Department of Yunnan Province, China (grant No. ZD201504).

\section{References}

[1] X.C. He, F.S. Gu, A. Ball, Prog. Mater. Sci. 65, 1 (2014).

[2] X.C. He, L. Zhao, C.J. Deng, B.Y. Xing, F.S. Gu, A. Ball, Mater. Des. 65, 923 (2015).

[3] X.C. He, Int. J. Adhes. Adhes. 53, 34 (2014).

[4] C.J. Lee, J.Y. Kim, S.K. Lee, D.C. Ko, B.M. Kim, Mater. Des. 31, 1854 (2010).

[5] X.C. He, L. Zhao, H.Y. Yang, B.Y. Xing, Y.Q. Wang, C.J. Deng, F.S. Gu, A. Ball, Comput. Mater. Sci. 94, 58 (2014).

[6] X.C. He, Y. Zhang, B.Y. Xing, F.S. Gu, A. Ball, Mater. Des. 71, 26 (2015).

[7] S. Gao, L. Budde, Int. J. Mach. Tool Manufact. 34, 641 (1994).

[8] J. Mucha, Mater. Des. 32, 4943 (2011).

[9] J.P. Varis, J. Mater. Process. Technol. 132, 242 (2003).

[10] J.P. Varis, J. Mater. Process. Technol. 172, 130 (2006).

[11] F. Lambiase, A. Di Ilio, J. Mater. Process. Technol. 230, 109 (2016).

[12] F. Lambiase, Mater. Des. 87, 606 (2015). 